\title{
Desempenho do Núcleo de Atuação em Desastres e Grandes Empreendimentos da Defensoria Pública do Estado do Espírito Santo: Experiências e desafios na desnaturalização dos desastres
}

Performance of the Center for Action in Disasters and Large Enterprises of the Public Defender's Office of the State of Espirito Santo: Experiences and challenges in the denaturalization of disasters

Desempeño del Centro de Acción en Desastres y Grandes Empresas de la Defensoría Pública del Estado de Espírito Santo: Experiencias y desafíos en la desnaturalización de desastres

Rafael Mello Portella Campos ${ }^{1}$

\section{Resumo}

CAMPOS, R. M. P.. Desempenho do Núcleo de Atuação em Desastres e Grandes Empreendimentos da Defensoria Pública do Estado do Espírito Santo: Experiências e desafios na desnaturalização dos desastres. Rev. C\&Trópico, v. 45, n. 2, p. 209-220, 2021. DOI: https://doi.org/10.33148/cetropicov45n2(2021)art13

A Defensoria Pública, instituição de justiça cuja função é promover os direitos humanos e a defesa jurídica dos vulneráveis, habitualmente atua na defesa de comunidades atingidas por contextos de crises e desastres. É por meio dessa experiência que se construiu o Núcleo de Atuação em Desastres e Grandes Empreendimentos (NUDEGE) da Defensoria Pública do Estado do Espírito Santo, cujas atribuições visam a defesa do direito ao meio ambiente ecologicamente equilibrado, a orientação jurídica e a promoção dos direitos humanos de pessoas vítimas de desastres e de impactos por grandes empreendimentos. O presente trabalho apresenta um compilado de experiências no seu primeiro ano de atuação.

Palavras-chave: Defensoria pública. Mobilização do Direito. Desnaturalização dos desastres.

\section{Abstract}

CAMPOS, R. M. P. Performance of the Center for Action in Disasters and Large Enterprises of the Public Defender's Office of the State of Espírito Santo: Experiences and challenges in the denaturalization of disasters. Rev. CઐTrópico, v. 45, n. 2, p. 209-220, 2021. DOI: https://doi.org/10.33148/cetropicov45n2(2021)art13

1 Defensor Público do Estado do Espírito Santo. Mestrando em Ciências Sociais pela Universidade Federal do Estado do Espírito Santo. Integrante do Núcleo de Estudo, Pesquisa e Extensão em Mobilizações Sociais (ORGANON). Email: rafaelmpcampos@hotmail.com. ORCID: https://orcid.org/0000-0003-0663-2300 
The Public Defender's Office, a justice institution whose function is to promote human rights and the legal defense of the vulnerable, usually acts in defense of communities affected by contexts of crisis and disaster. It is through this experience that the Nucleus for Action in Disasters and Large Enterprises (NUDEGE) of the Public Defender of the State of Espirito Santo was built, whose attributions aim to defend the right to an ecologically balanced environment, legal guidance and the promotion of rights human rights of people victims of disasters and impacts by large projects. This work presents a compilation of experiences in its first year of work.

Keywords: Public Defender's Office. Legal Mobilization. Denaturalization of disasters.

\section{Resumen}

CAMPOS, R. M. P.. Desempeño del Centro de Acción en Desastres y Grandes Empresas de la Defensoría Pública del Estado de Espírito Santo: Experiencias y desafíos en la desnaturalización de desastres. Rev. C\&Trópico, v. 45, n. 2, p. 209-220, 2021. DOI: https://doi. org/10.33148/cetropicov45n2(2021)art13

La Defensoría Pública, institución de justicia cuya función es promover los derechos humanos y la defensa jurídica de los vulnerables, suele actuar en defensa de las comunidades afectadas por contextos de crisis y desastre. Es a través de esta experiencia que se construyó el Núcleo de Acción en Desastres y Grandes Empresas (NUDEGE) de la Defensoría Pública del Estado de Espírito Santo, cuyas atribuciones apuntan a defender el derecho a un medio ambiente ecológicamente equilibrado, la orientación jurídica y la promoción de derechos humanos de las personas víctimas de desastres e impactos de grandes proyectos. Este trabajo presenta una recopilación de experiencias en su primer año de trabajo.

Palabras clave: Defensoría Pública. Movilización legal. Desnaturalización de desastres. 


\section{Introdução}

A Defensoria Pública, instituição de justiça cuja função é promover os direitos humanos e a defesa jurídica dos vulneráveis, possui uma vocação natural no atendimento de comunidades atingidas por contextos de crises e desastres. É por meio dessa experiência que se construiu o Núcleo de Atuação em Desastres e Grandes Empreendimentos (NUDEGE) da Defensoria Pública do Estado do Espírito Santo, cujas atribuições visam à defesa do direito ao meio ambiente ecologicamente equilibrado, à orientação jurídica e à promoção dos direitos humanos de pessoas vítimas de desastres e de impactos gerados por grandes empreendimentos no estado do Espírito Santo.

Propõe-se uma atuação essencialmente fundamentada nos aspectos sociais, ou seja, construída a partir da interação entre a instituição de justiça e a coletividade atingida, de modo a se compreender e a se pensar estratégias de atuação mais condizentes com os anseios daqueles vitimados pelo contexto crítico. A expansão da atuação, ainda que com todas as limitações da pandemia do COVID 19, permite a apresentação de um resultado preliminar dessas primeiras experiências e em que medida podem contribuir para a desnaturalização dos desastres.

\section{A Defensoria Pública e a atuação em contextos de crises e desastres}

Quando se fala em vocação da Defensoria Pública, ou seja, a capacidade ou inclinação natural da atuação da instituição em contextos de crises e desastres, pretende-se chamar a atenção para a sua precípua função em promover os direitos humanos e a defesa dos direitos individuais e coletivos, de forma integral e gratuita, aos necessitados ${ }^{2}$. Estes últimos são compreendidos em uma concepção mais ampla de caracterização das vulnerabilidades sociais que podem reduzir a sua capacidade de autodeterminação e afirmação para além do aspecto econômico, abrangendo também questões organizacionais, grupos vulneráveis ${ }^{3}$, situações episódicas ou transitórias de vulnerabilidade, dentre outras (ESTEVES; SILVA, 2018).

No estado do Espírito Santo, as primeiras experiências em contextos de crises e desastres ocorreram a partir da atuação do Núcleo de Defesa Agrária e Moradia (NUDAM) ${ }^{4}$. Em novembro de 2015, com o rompimento da barragem de Fundão,

2 O art. 134 da Constituição Federal dispõe que: A Defensoria Pública é instituição permanente, essencial à função jurisdicional do Estado, incumbindo-lhe, como expressão e instrumento do regime democrático, fundamentalmente, a orientação jurídica, a promoção dos direitos humanos e a defesa, em todos os graus, judicial e extrajudicial, dos direitos individuais e coletivos, de forma integral e gratuita, aos necessitados, na forma do inciso LXXIV do art. $5^{\circ}$ desta Constituição Federal. (BRASIL, 1988)

3 Uma das diretrizes usadas para balizar o conceito de vulnerável são as Regras de Brasília sobre Acesso à Justiça das Pessoas em Condição de Vulnerabilidade, documento organizado pela Conferência Judicial Ibero Americana (2008).

4 Instituído pelo Ato Normativo DPES n 450 de 16 de junho de 2015, o Núcleo de Defesa Agrária e Moradia (NUDAM), iniciou as suas atividades em julho de 2015, mediante Portaria DPES n 478 de 29 de junho de 2015. Trata-se de núcleo especializado de caráter de atuação coletiva, em temas como: direito à moradia adequada, regularização fundiária, direito à cidade, direito urbanístico, remoções compulsórias, dentre outros temas circundantes. 
Mariana/MG, e os seus impactos nos municípios capixabas, foi também o NUDAM que construiu a estratégia de atuação e buscou atender os atingidos pelo desastre do Rio Doce ${ }^{5}$. Essas duas grandes áreas de atuação levaram a Defensoria Pública a ter contato com segmentos da sociedade, alijados de políticas públicas ou medidas reparatórias de responsáveis pelas situações em que vivem, vivem em extrema vulnerabilidade.

Sejam famílias na iminência de perderem as suas casas, desalojadas por chuvas ou deslizamentos de terra, ou comunidades pesqueiras que não mais podem exercer a sua atividade e não possuem acesso a medidas reparatórias, as características do grupo a ser atendido são melancolicamente similares. Tratam-se de pessoas que perderam o pouco que tinham, e de uma hora para outra, precisarão de uma gama de políticas públicas para se restabelecerem. A dramaticidade reside ainda na insuficiência da resposta estatal, o que se revelou uma constante em toda a sua atuação.

Um dos casos mais emblemáticos da atuação do NUDAM foi o atendimento das famílias desalojadas do Morro da Boa Vista, São Torquato, Vila Velha/ES, em decorrência do deslizamento de uma rocha de três toneladas, em janeiro de 2016. O fato acarretou a remoção das famílias do local e posteriormente o pagamento de indenizações e direcionamento dos moradores aos programas habitacionais.

No ano de 2018, a comunidade de Piedade, Vitória/ES, solicitou auxílio ao NUDAM tendo em vista a expulsão de 40 famílias por causa de disputas relacionadas ao tráfico de drogas. Por meio de uma ação civil pública, a Defensoria conseguiu promover a atuação intersetorial do Estado, que se recusava a tomar ações efetivas na defesa da comunidade. Desde o início, buscou-se enxergar a crise de segurança pública a partir dos efeitos sociais, gerados pela resposta inadequada do Estado e o importante papel da comunidade na construção de soluções para os inúmeros problemas sociais existentes no território.

Além delas, inúmeras outras atuações focaram no atendimento de pessoas vítimas de remoções compulsórias, sejam relacionadas às áreas privadas ou públicas, sem perspectivas de assistência social ou medidas efetivas de reassentamento. Não raro houveram casos em que o acionamento de instâncias policiais e da rede de proteção aos Defensores de Direitos Humanos foi necessária para cessar ameaças por parte de supostos proprietários a ocupantes de loteamentos ${ }^{6}$.

Reconhecendo a transversalidade de áreas de atuação e a íntima relação do tema da moradia com outras questões como meio ambiente, direitos humanos, segurança hídrica e alimentar, saúde, dentre tantas outras, o NUDEGE é criado no ano de $2020^{7}$, com a perspectiva de aprimorar a atuação da Defensoria. Conjugado com

5 Desde novembro de 2015, a Defensoria Pública do ES atua no âmbito do desastre ambiental, tendo inicialmente criado grupo de trabalho especial para prestar atendimento aos atingidos (Grupo SOS Rio Doce), conforme regulamentado pelo Ato Normativo ${ }^{\circ} 003$ de 13 de novembro de 2015 . A partir de 22 de agosto de 2016, em decorrência da Portaria n 518, o Núcleo de Defesa Agrária e Moradia, doravante NUDAM, passou a acumular dentre as suas atribuições as atividades outrora desempenhadas pelo referido Grupo de Trabalho.

6 Disponível em: https://www.portaltemponovo.com.br/audiencia-publica-discute-regularizacao-fundiaria-em-belvedere/ - Acesso em 16 de dezembro de 2021.

7 Ato Normativo no 16 de 14 de fevereiro de 2021. 
uma atuação consolidada na área do direito à moradia, busca-se conferir um enfoque socioambiental à atuação, de modo que a atuação de ambos os núcleos tenha mais efetividade no atendimento às comunidades vulneráveis do Estado.

\section{Os primeiros passos do NUDEGE na temática dos desastres no Estado do Espírito Santo}

Para se falar a respeito da atuação do NUDEGE, é importante delimitar o conceito de desastre usado no seu ato normativo e os conceitos teóricos empregados. Nesse sentido, "Desastres são acontecimentos coletivos trágicos nos quais há perdas e danos súbitos e involuntários que desorganizam, de forma multidimensional e severa, as rotinas de vida (por vezes, o modo de vida) de uma dada coletividade" (ZHOURI et al. 2016). Sob outro ponto de vista, destaca-se a redação usada na Nota Pública do Curso de Desastres ${ }^{8}$, que dispõe que o conceito contemporâneo de desastre focaliza o significativo estresse social decorrente de uma circunstância física adversa (súbita ou processual), cujos danos materiais e imateriais implicados superam a capacidade endógena de recomposição dos grupos sociais afetados assim como o suporte proveniente do meio técnico-operacional local.

Partindo-se dos conceitos acima referidos e das experiências sinteticamente descritas, o NUDEGE trabalha com a concepção de que desastres são todo acontecimento que promove rupturas no modo de vida e na dinâmica social e ambiental de uma determinada coletividade, conforme dispõe o art. $1^{\circ}$, I, do Ato Normativo $\mathrm{n}^{\circ} 16$ de 14 de fevereiro de 2021. Ainda que o conceito não observe todas as características apontadas na sociologia dos desastres, é suficientemente objetivo para pautar a nova atuação proposta.

Além disso, cabe destacar o conceito de grandes empreendimentos, assim definido como obras ou serviços realizados por ato público ou privado, que causem impactos ambientais a uma determinada coletividade e que afetem a saúde, a segurança e o bem-estar da população; as atividades sociais e econômicas; a biota; as condições estéticas e sanitárias do meio ambiente; e a qualidade dos recursos ambientais.

Adiante, o ato normativo prevê que o NUDEGE atuará na orientação e assistência jurídica das coletividades em situação de vulnerabilidade, de forma integrada com a sociedade civil e em parceria com o poder público e entidades privadas, privilegiando a atuação preventiva e estratégica, com o objetivo de promover a redução de riscos de desastres e dos impactos sociais e ambientais relacionados à implementação de grandes empreendimentos no estado do Espírito Santo.

8 O curso de formação de Defensores Públicos sob o tema: "Desastres: dimensões sociais", realizado nos dias 15 e 16 de dezembro de 2016, realizado no município de Vila Velha/ES. O curso foi organizado pela Defensoria Pública, Pelo Núcleo De Estudos e Pesquisas Sociais em Desastres - Neped da Universidade Federal De São Carlos - Ufscar e o Organon - Núcleo De Estudo, Pesquisa E Extensão Em Mobilizações Sociais Do Departamento e do Programa De Pós-Graduação Em Ciências Sociais Da Universidade Federal Do Espírito Santo - Ufes (2016) 
Ademais, cabe ao NUDEGE atuar na defesa dos direitos humanos, das garantias fundamentais previstas na Constituição Federal e nos Tratados Internacionais e na observância destes preceitos pelo Poder Público e pelas sociedades empresárias no desenvolvimento de suas atividades, sobretudo aquelas com potencial de causar impactos sociais e ambientais.

Outro ponto de destaque é a previsão de se priorizar a atuação direta nos territórios atingidos, com o fomento de soluções cooperativas que privilegiem a participação popular na gestão de crises, na fiscalização da implementação de grandes empreendimentos e na elaboração de políticas públicas, assim como a promoção e a conscientização dos direitos humanos, da cidadania e do ordenamento jurídico por meio de mecanismos participativos, inclusivos e desburocratizados, que primem pela coloquialidade e pelo compartilhamento de conhecimentos que possibilitem à comunidade tomar consciência da realidade e da sua própria capacidade de transformar.

Por fim, caberá ao NUDEGE promover uma atuação estratégica de caráter multidisciplinar, considerando a complexidade da atuação em contextos de crises e desastres, bem como a necessidade de implementação de ações estruturantes para o seu enfrentamento, além de servir como interlocutor entre o poder público e a sociedade civil no planejamento, elaboração e proposição de políticas públicas e projetos de lei.

Estabelecido o retrospecto de atuação da Defensoria Pública e o marco normativo de atuação do NUDEGE, inicia-se, em agosto de 2020, a atuação do novo núcleo da Defensoria Pública.

Diferentemente do NUDAM, que iniciou a sua atuação na temática no marco zero, o NUDEGE herda a sua atuação no âmbito do desastre do Rio Doce. Como exemplo mais recente desta atuação ${ }^{9}$, ressalta-se o esforço concentrado na defesa da comunidade indígena do território de Comboios, que abrange a aldeia de Comboios e de Córrego do Ouro, totalizando 303 famílias. Atuando no assessoramento das lideranças e caciques, após um ano de negociação, é fechado acordo de indenização com a Fundação Renova.

A expansão da atuação para além do desastre do Rio Doce iniciou o atendimento dos quilombolas do município de Conceição da Barra, organizado em diversas comunidades. A partir de reuniões periódicas, chegam à Defensoria Pública preocupações como a construção da rodovia 422 no município, que prevê a passagem em territórios quilombolas; a constatação da existência de um lixão clandestino desativado que ainda gera impactos ambientais; o diálgo com empresas locais para fornecimento de água; entre outras demandas.

O recorte socioambiental, calcado na defesa do meio ambiente ecologicamente equilibrado e na defesa das comunidades tradicionais, também foi desenvolvido a partir do acionamento de comunidades pesqueiras do estado. Cita-se, por exemplo, a preocupação das associações de pescadores do município de Serra com o Plano de Compensação da Atividade Pesqueira da Petrobras (PCAP), que prevê a construção de

9 Dificilmente poderíamos sintetizar a atuação da Defensoria Pública do ES no caso Rio Doce em poucos parágrafos. Ela é citada com o principal objetivo de demonstrar as principais experiências que moldaram o NUDEGE. Para mais informações: https://www.defensoria.es.def.br/site/index.php/nucleo-de-atuacao-em-desastres-e-grandes-empreendimentos/ - Acesso em 16 de dezembro de 2021. 
uma unidade de beneficiamento de pescado na região. O NUDEGE é chamado a interceder pelos pescadores devido à dificuldade de comunicação com a empresa e com o poder público municipal. Outra demanda de especial relevância veio da comunidade pesqueira da praia do Suá, Vitória/ES, preocupada com a concessão do Terminal Pesqueiro Público de Vitória, localizado no bairro Jesus de Nasareth e seus impactos sociais na região.

Além do eixo de atuação afeto aos impactos de grandes empreendimentos na vida das pessoas, usualmente causadores de conflitos ambientais, o NUDEGE passou a desenvolver atuações em temáticas de alcance mais difusas, como os impactos derivados de chuvas, deslizamentos, enchentes, secas e queimadas. Entretanto, e conforme será melhor explorado a seguir, os obstáculos a uma devida atuação nessa área ainda ensejarão esforços para a construção de rotinas de atuação efetivas e concretas na defesa das comunidades atingidas.

\section{A construção dos repertórios de atuação do NUDEGE e os obstá- culos ao atendimento das pessoas atingidas por desastres e impactos de grandes empreendimentos}

A partir dos casos acima analisados, o NUDEGE tem desenvolvido diferentes formas de atuação, a depender da existência de grupos determinados, determináveis ou indeterminados. Quando a Defensoria Pública é acionada por coletividades (grupos específicos, associações, movimentos sociais, entre outros), a atuação, por estar melhor delimitada, permite o estabelecimento da interação com a instituição de justiça e, com o tempo, o estabelecimento da confiança e o desenvolvimento conjunto de repertórios de atuação e do desenvolvimento de performances coordenadas (LOSEKANN, 2019).

Enxergar a Defensoria Pública dentro da mobilização do direito, isto é, como um recurso de interação política e social, à disposição do usuário do sistema de Justiça para que busque o acesso à justiça e à satisfação de suas demandas (MCCANN, 2010), confere à atuação um outro enquadramento, dotado de características emocionais e focadas na interação entre a pessoa atingida e a instituição de justiça (GOFFMAN, 1974 apud ANDERSEN, 2008).

O frame, quadro ou enquadramento, a partir das lições de Goffman, é um conjunto de referenciais que são utilizados para entender uma situação, organizar a percepção da realidade ao redor e decidir como agir (MARTINO, 2021). Para uma instituição de justiça como a Defensoria Pública, considerar em seu enquadramento a necessidade de desnaturalizar a concepção de desastres e fortalecer os vínculos comunitários significa desenvolver repertórios de atuação que aproximem as comunidades atingidas e permitam a construção em conjunto dos caminhos necessários para a reivindicação de direitos.

$\mathrm{Na}$ atuação em face de conflitos ambientais, como é o caso do Desastre do Rio Doce, ou nos impactos gerados por grandes empreendimentos, como a construção de rodovias e depósitos de rejeitos, a aproximação com as comunidades atingidas, respeitando-se os seus saberes, modos de vida, organização e determinação, permitiu 
o desenvolvimento de estratégias exitosas de atuação, permitindo não só o acesso a reparações e compensações individuais e coletivas, mas também à afirmação de direitos instrumentais fundamentais para a sua visibilidade. Direitos humanos instrumentais servem para garantir ou operacionalizar a realização dos direitos humanos básicos na vida de cada pessoa (COELHO, 2002). Sob outro enfoque, os direitos ambientais procedimentais, dessa forma, consagram a tríade: direito de participação social, direito de acesso à informação e acesso à justiça como elementares para a efetivação de direitos materiais (SARLET e FENSTERSEIFER, 2018).

Desta forma, a atuação da Defensoria Pública e a reflexão acerca do seu repertório de atuação deve passar, primordialmente, pelo reconhecimento do protagonismo das comunidades atingidas. Estabelecido este ponto, deve-se problematizar a construção de estratégias que abarquem não só a judicialização como também ações extrajudiciais que possam contribuir para a resolução dos problemas, para a sua visibilidade e fomento à discussão nos espaços públicos. Nesse sentido:

$\mathrm{O}$ acesso que as instituições judiciais concedem aos cidadãos para eles fazerem valer seus direitos é um direito-chave e um indicador do vigor democrático de uma sociedade. A capacidade das autoridades jurídicas para acelerar ou gerar a atividade judicial em defesa dos direitos é uma medida de vitalidade (MCCANN, 2010).

A valorização da interação com as pessoas atingidas também traz a responsabilidade de se manter o contato de forma habitual, especialmente com a presença de Defensores e Defensoras nos territórios atendidos. O tempo de resolução das demandas, muitas vezes por traduzirem problemas estruturais, é um fator a ser considerado, pois pode vir a desestimular e acarretar a desmobilização da coletividade. Não raro, terceiros aparecem nos territórios com promessas de resolução fácil dos problemas (advogados particulares, políticos, entre outros), colocando em risco o desenvolvimento de todo um trabalho.

Sob outro recorte, quando a Defensoria Pública se depara com situações críticas, de difícil resolução ou inviabilidade de determinação de atingidos, a atuação proposta perde tração. A estruturação de uma atuação participativa também traz dificuldades. Além do contexto da pandemia da COVID 19, que diminuiu sobremaneira o contato com as comunidades atendidas de forma presencial, e o atendimento às coletividades impactadas por desastres naturais, como chuvas, deslizamentos, cheias e secas revelou-se extremamente problemático.

Isso se dá, primeiramente, pela dificuldade de se construir, com agilidade, a rede de atores que possam auxiliar a Defensoria Pública no contato com as lideranças locais, associações, sindicatos e demais entidades da sociedade civil. $\mathrm{O}$ atendimento, por ser difuso e fragmentado, acaba chegando à Defensoria de forma individual e esparsa, não permitindo a construção de uma relação mais efetiva e duradoura com as 
localidades afetadas. Essa relação é fundamental para se desenvolver, a médio e longo prazo, atividades de educação em direitos, diagnóstico e atuação para a resolução de problemas crônicos e conscientizar a respeito da adoção de medidas de prevenção e redução de riscos, preparando a comunidade para futuras situações.

Ato contínuo, não sendo possível, como regra geral, adotar-se uma mesma linha de atuação similar ao acionamento em casos de impactos de grandes empreendimentos, o NUDEGE tem buscado se inserir na rede de atores do Estado que lida com desastres. Contatos com o Poder Público, sobretudo com as Defesas Civis Estadual e Municipais, redes de assistência social, Defensoria Pública da União, Ministério Público Federal, entre outros, auxiliarão no acionamento mais rápido e no diálogo com as comunidades atingidas.

A título de exemplo sobre as dificuldades de atuação em contextos de chuvas, o primeiro relatório preliminar sobre a situação de 32 municípios capixabas no início do ano de 2021, que abrangem a região metropolitana e o sul do Estado, expõe que apenas oito atenderam às solicitações da Defensoria Pública. Desse pequeno grupo, poucas informações puderam ser usadas num efetivo diagnóstico.

O contato formal com a Defesa Civil, portanto, deve-se levar em conta a realidade da precarização desses órgãos, tendo em vista que muitas contam com poucos funcionários temporários, poucos recursos e enorme dificuldade de atender as demandas em momentos críticos. Já aconteceu, em algumas situações, de se ter como resposta que a demanda da Defensoria Pública não pode ser atendida porque o funcionário está em diligência externa, atendendo tantos outros problemas.

Para contornar essa questão, além da inserção gradativa na rede de atores públicos que atuam com riscos e desastres no Estado, o NUDEGE construiu parcerias. No ano de 2021, buscou-se contatos com centros de pesquisa, destacando-se o Núcleo de Estudos Urbanos e Socioambientais (NEUS), da Universidade de Vila Velha, coordenado pela Professora Teresa Cristina da Silva Rosa, bem como com o Núcleo de Estudos e Pesquisas Sociais em Desastres (NEPED), da Universidade Federal de São Carlos, coordenado pela Professora Norma Valêncio. Além disso, no município de Vila Velha, a Câmara de Vereadores, por meio da vereadora Patrícia Crizanto, tem atuado com a Defensoria Pública para construir estratégias de atuação com comunidades e auxiliar no enfrentamento de problemas estruturais, sejam relacionados às chuvas e enchentes - muito comuns no município - como também em relação a empreendimentos e seus impactos para a sociedade.

Portanto, considerando as primeiras reflexões sobre a atuação do NUDEGE, percebe-se a necessidade de adoção de estratégias de atuação diferentes a depender de inúmeros referenciais a serem colhidos da situação de crise ou desastre. O grau de interação com a Defensoria Pública, organização social, conscientização acerca dos seus direitos, existência de rede com demais atores que auxiliem na mobilização, são alguns dos pontos que permitiram maior ou menor êxito nas atuações até então desenvolvidas. É importante a construção de alternativas que permitam que a atuação consiga chegar à vítima, ainda que esses fatores ora listados não sejam pungentes. 


\section{Conclusões}

Desnaturalizar os desastres implica uma mudança de percepção institucional necessária e urgente. Conforme exposto, a partir das primeiras atuações voltadas à defesa do direito de moradia, a Defensoria Pública, em pouco tempo, se deparou com situações de crises e desastres que ensejaram a revisão da sua forma de agir e a problematização de outras nuances que se agregavam ao primeiro recorte de atuação. A defesa do direito à moradia adequada passou a andar conjugado com o direito ao meio ambiente ecologicamente equilibrado, o direito à saúde e assistência social, o direito à segurança, entre tantos outros.

A atuação das instituições de justiça a fim de contribuir para o movimento de desnaturalização dos desastres precisam afastar ações que impliquem o atendimento burocrático e desinteressado das vítimas de desastres (VARGAS, 2014). A Defensoria Pública, por ter em sua atribuição o atendimento às pessoas em situação de vulnerabilidade, bem como a promoção dos direitos humanos, têm especial responsabilidade no desenvolvimento de estratégias de atuação que reconheçam a necessidade de se dedicar recursos humanos e logísticos àquelas pessoas em situação de extrema vulnerabilidade.

Portanto, há de se ter atenção na atuação para não contribuir com estigmatização das vítimas a partir da desconsideração da sua dor e de suas perdas. Isso pode ocorrer através da ação autoritária de autoridades, da atuação benemerente de movimentos sociais a partir da revitimização das pessoas atingidas, ou mesmo pela pressa em repercutir o caso, que reafirma pré concepções parciais incompletas ou equivocadas do problema (VALENCIO; VALENCIO, 2018).

A Defensoria Pública do Estado do Espírito Santo, ao criar um núcleo de atuação especializada para a temática, busca problematizar a complexidade desse tipo de atuação e conferir a sensibilidade necessária para o devido atendimento às vítimas de desastres. 


\section{Referências}

ANDERSEN, Ellen Ann. Out of the Closets and into the Courts. Michigan: The University of Michigan Press, 2008.

COELHO, Edihermes Marques. Os direitos fundamentais em face da globalização de mercados e o garantismo como referência jurídica necessária. 2002. Tese (Doutorado em Direito) Universidade Federal de Santa Catarina. Orientador: Sérgio Urquhart de Cademartori.

CONFÊRENCIA Judicial Ibero Americana. Regras de Brasília Sobre Acesso à Justiça Das Pessoas Em Condição De Vulnerabilidade. Brasília, 2008.

LOSEKANN, Cristiana. Performances coordenadas e experiências compartilhadas na mobilização do direito em conflitos ambientais - A contribuição do pragmatismo de John Dewey. PLURAL (SÃO PAULO. ONLINE), v. 26, p. 177-199, 2019.

Defensoria Pública do Estado do Espírito Santo. Núcleo de Atuação em Desastres e Grandes Empreendimentos. NUDEGE. Relatório Preliminar referente aos municípios da região metropolitana e sul do Estado, 2021.

ESTEVES, D.; SILVA, F. R. A. Princípios Institucionais da Defensoria Pública. 3a ed. Rio de Janeiro: Forense, 2018.

MARTINO, Luís Mauro Sá. 10 lições sobre Goffman. Editora Vozes. 2021.

MCCANN, Michael W. Poder Judiciário e Mobilização do Direito: Uma perspectiva dos "usuários". In: DUARTE, Fernanda; KOERNER, Andrei (Org.). Rev. da Esc. da Magistr. Reg. Fed. / Esc. da Magistr. Reg. Fed. Trib. Reg. Fed. da 2a Região. Cad. Temáticos - Justiça Const. no Bras. Política e Direito. Rio de Janeiro: EMARF - TRF 2a Região, 2010. p. 175-196.

SARLET, Ingo Wolfgang; FENSTERSEIFER, Tiago. Algumas notas sobre a dimensão ecológica da dignidade da pessoa humana e sobre a dignidade da vida em geral. In: MOLINARO, Carlos Alberto; MEDEIROS, Fernanda Luiza Fontoura de; SARLET, Ingo Wolfgang; FENSTERSEIFER, Tiago (coord.). A dignidade da vida e os direitos fundamentais para além dos humanos: uma discussão necessária. Belo Horizonte: Fórum, 2008.

VARGAS, Dora. Desastres - Autoridades e Afetados: desiguais condições de poder ou esforço de negação do dissenso. In: VALENCIO, Norma; SIENA, Mariana (Org.). Sociol. dos Desastr. Construção, interfaces e Perspect. Vol. IV. 1a edição ed. São Carlos: RiMa Editora, 2014. p. 255-280.

VALENCIO, Norma; VALENCIO, ARTHUR . O assédio em nome do bem: Dos sofrimentos conectados à dor moral coletiva de vítimas de desastres. LUMINA (JUIZ DE FORA), v. 12, p. 19-39, 2018. 
